04

\title{
Исследование сильноточного разряда в атмосфере, инициированного взрывом короткой проволоки, методами цветной сверхскоростной фоторегистрации
}

\author{
(C) Н.В. Плетнев \\ Институт общей физики им. А.М. Прохорова РАН, \\ 119991 Москва, Россия \\ e-mail: pletnev@kapella.gpi.ru
}

(Поступило в Редакцию 26 октября 2017 г.)

Описан метод скоростной фотосъемки в режиме щелевой развертки, световых явлений, возникающих на стадии электрического пробоя в атмосфере и в канале, инициированном взрывом проволоки. Приведены характеристики и особенности фоторегистрации камерой SFR-1 на цветные и спектрозональные негативные аэрофотопленки, чувствительные в видимой и ближней инфракрасной области оптического спектра. На фотограммах в цвете удалось визуализировать мелкомасштабные неоднородности, токопроводящий канал и его „оболочку“, выбросы вещества, ударные волны в плазме. Данная методика позволила регистрировать вторичную ударную волну в плазме на оси разряда при взрыве коротких (длиной $\approx 15 \mathrm{~mm}$ ) медных и нихромовых проволок диаметром 100-150 $\mu$ m при запасенной энергии $\sim 100 \mathrm{~J}$. В момент кумуляции в плазме на оси разряда образовалась „горячая точка“ с минимальным размером $\sim 0.5 \mathrm{~mm}$, которая, возможно, является источником узконаправленного когерентного излучения с энергий рентгеновских квантов 10-30 keV. Обсужден механизм кумуляции на основе закономерностей явления z-рinch в разряде, инициированном взрывом проволоки.

DOI: 10.21883/JTF.2018.08.46305.2534

\section{Введение}

При исследовании световых явлений, сопутствующих пространственно-временному развитию канала электрического пробоя в атмосфере, часто используют метод сверхскоростной фоторегистрации, который разделяется на две группы: методы покадровой съемки (лупы времени) и методы щелевой развертки (фотограммы) [1,2].

Метод щелевой развертки применяется в тех случаях, когда необходимо зафиксировать характер перемещения объекта (свечения) вдоль какого-либо направления, которое задается щелью. Для проведения фотосъемки в настоящей работе использовался сверхскоростной фоторегистратор типа SFR-1, схема которого в варианте щелевой развертки будет рассмотрена далее. В качестве регистрирующей среды в SFR-камерах обычно применяют черно-белую изопанхромную пленку, чувствительную в видимой части спектра. Целью такой фоторегистрации является главным образом получение качественной информации о процессах и определение их характеристик (скоростей газа, ударных волн и т.д.). При такой съемке другие очень существенные достоинства научной фотографии, которые и определяют ее как экспериментальный метод, а именно измерительная съемка (точное определение геометрических размеров), применение тонового и цветового контрастов для исследования температурных, энергетических, фазовых и прочих характеристик в снимаемом объекте, использовались крайне редко [3]. По-видимому, основной причиной этого являлась низкая светочувствительность цветных фотоматериалов. Задача настоящей работы заключается в том, чтобы использовать новые возможности в методе сверхскоростной фоторегистрации в связи с появлением высокочувствительных цветных и спектрозональных аэрофотопленок, разработанных для съемок с орбит и с воздуха.

В конце шестидесятых годов в СССР кроме цветных аэрофотопленок типа ЦN-4, ЦN-5 были разработаны также многослойные спектрозональные аэрофотопленки типа SN-6, SN-10, SN-15, позволяющие регистрировать в условных цветах весь спектр актиничного излучения, включая IR-диапазон длин волн. Чувствительность таких фотоматериалов к излучению составляет ISO 300-600 и более, что позволяет регистрировать излучение с энергетической яркостью $0.01 \mathrm{~W} / \mathrm{m}^{2}$ и меньше. B IR-диапазоне чувствительность ограничивается длиной волны $\approx 1.15 \mu \mathrm{m}$, что соответствует температуре $T \approx 2500 \mathrm{~K}$ в максимуме излучения абсолютно черного тела.

Особенности цветной инфракрасной съемки, так называемой съемки в условных цветах, были рассмотрены Иорданским в работе [4]. Наличие, наряду с тоновым, и цветового контраста в ближнем IR-диапазоне существенно повышает информативность снимков (до $10^{4}$ раз), что ведет к повышению эффективности исследований, а в ряде случаев к получению качественно новых результатов. Современные методы обработки и анализа результатов исследований на РС делают предпочтительным использование таких методов. Следует отметить, что указанные фотоэмульсии разработаны главным образом для съемок с орбит и с воздуха с целью так называемого дистанционного многоспектрального зондирования [4,5]. Они сенсибилизированы оптимально к излучению, отражен- 

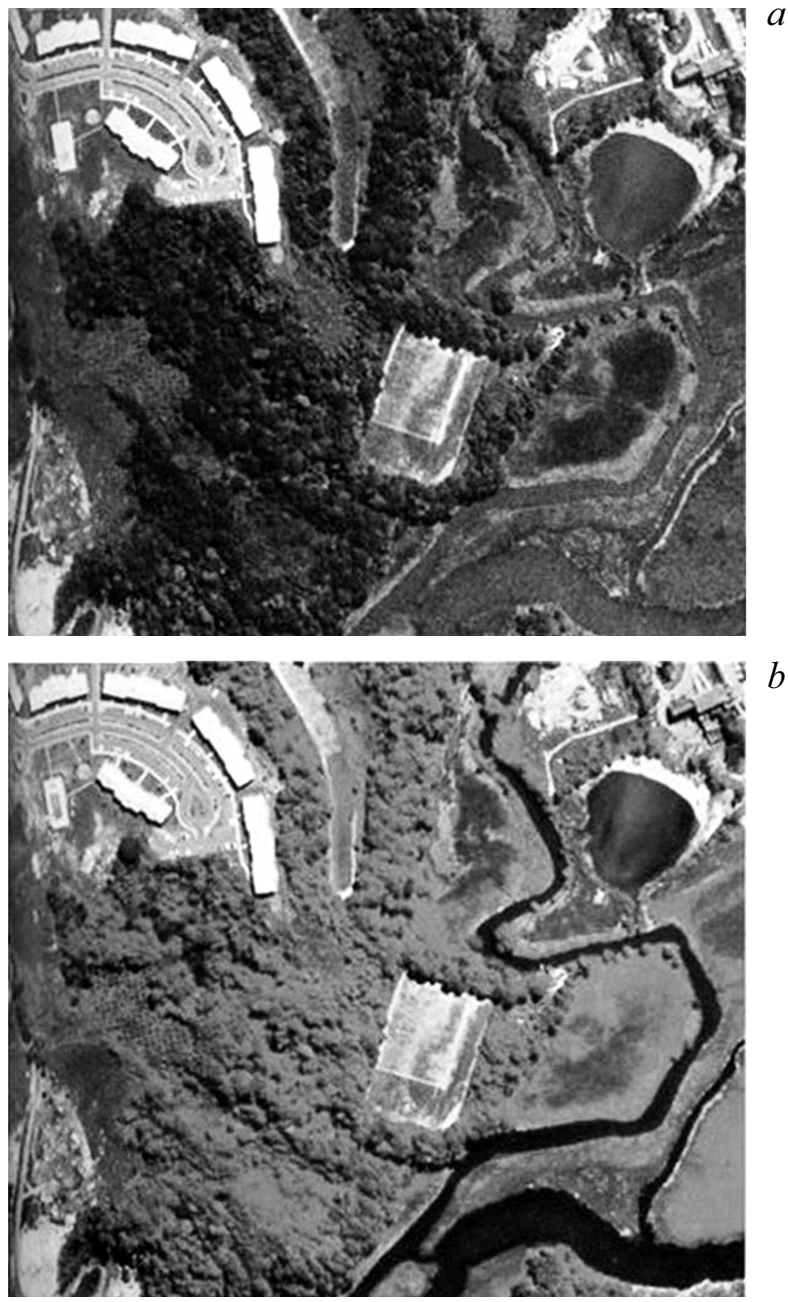

Рис. 1. Аэрофотоснимки местности, полученные на цветной $(a)$ и спектрозональной $(b)$ пленках фирмы KODAK Color Infrared Aerial Film [5].

ному от природных объектов, которое по своим характеристикам значительно отличается от исследуемого в настоящей работе излучения при электрическом пробое в атмосфере. В работе [5] приведены аэрофотоснимки местности, полученные на цветной и спектрозональной пленке фирмы KODAK Color Infrared Aerial Film. Ha фотоснимках, представленных на рис. 1, следует отметить более высокий контраст изображения отдельных элементов местности (поверхности воды), полученный на спектрозональной пленке.

Возможности фотосъемки фоторегистратором типа SFR-1 при использовании цветных и спектрозональных пленок в качестве регистрирующей среды для исследования электрического пробоя в атмосфере были реализованы в ранее опубликованной работе [6]. В настоящей работе исследовался импульсный электрический разряд в атмосфере между двумя горизонтально расположенными на расстоянии $l_{0} \approx 3 \mathrm{~mm}$ молибденовыми электродами конической формы и электрический пробой, инициированный взрывом проволоки (EW) $\varnothing 100-150 \mu \mathrm{m}$ из
$\mathrm{NiCr}$ и меди, длиной $L \approx 15 \mathrm{~mm}$. Основным результатом работы [6] являлось то, что при локальном термодинамическом равновесии источника излучения регистрируемое на пленке изображение (фотограмма) получалось цветным, так как каждой излучающей точке на объекте с определенной температурой в данный момент времени соответствует определенная точка, регистрируемая на пленке. Результаты исследования электрического пробоя в парах $\mathrm{EW} \varnothing 100-150 \mu \mathrm{m}$ из $\mathrm{NiCr}$ и меди до настоящего времени опубликованы не были. Это связанно с трудностью интерпретации полученных ранее результатов и необходимостью проведения дополнительных экспериментов, которые и были выполнены в настоящей работе.

Как альтернативный вариант SFR в методе щелевой развертки для исследования процессов в канале искрового разряда в различных спектральных зонах, в работе [7] использовался электронно-оптический преобразователь (ЕОР). С его помощью было проведено исследование пространственно-временного развития свечения канала и распространение первичной ударной волны. Развертка изображения на экране преобразователя получается путем отклонения потока фотоэлектронов линейно изменяющимся во времени магнитным полем, создаваемым током, протекающим в отклоняющих катушках. Такая развертка обладает значительным преимуществом перед зеркальной разверткой в SFR. Если с помощью вращающего зеркала в SFR можно получить скорость развертки до $3-4 \mathrm{~km} / \mathrm{s}$, то с ЕОР эту скорость можно довести до $300 \mathrm{~km} / \mathrm{s}$ [7]. Применение ЕОР с кислородносеребряно-цезиевым фотокатодом позволяет исследовать пространственно-временное развитие свечения канала разряда не только в видимой (3700-7000 $\AA$ ), но и IR-области спектра (7000-10000 $)$. В установке отсутствуют быстро движущиеся части, требующие высокой точности при их изготовлении и юстировке. Несмотря на эти преимущества, одновременная многоспектральная фотосъемка свечения канала в видимой (две зоны спектра) и инфракрасной областях (одна зона спектра) в условных цветах с помощью ЕОР-камер практически невозможна.

Следует также отметить, что современные средства регистрации изображения в среднем IR-диапазоне $(2.5-5.5 \mu \mathrm{m})$ с помощью скоростных камер (FLIR SC7700M) в покадровом режиме (111 кадров в секунду) позволили получить качественно новые результаты. В частности, при наблюдении позитивных и негативных лидеров электрических разрядов, возникающих внутри облака, состоящего из отрицательно заряженных капель воды [8]. Однако данный тип камер не позволяет осуществлять одновременно многоспектральную фотосьемку свечения разряда.

\section{1. Структура экспериментального стенда}

Для проведения фотосъемки в настоящей работе использовался сверхскоростной фоторегистратор типа 
SFR-1. Следует отметить, что заводской вариант фоторегистратора позволяет фотографировать исследуемый самосветящийся объект с расстояния не менее $2 \mathrm{~m}$, по этой причине в оптическую схему SFR-1 далее вводится дополнительное переходное кольцо длиной $L \sim 90 \mathrm{~mm}$, которое позволяет получать изображение исследуемого объекта в масштабе $1.75: 1$

Система синхронизации, описанная далее, включает в себя разрядник - игнитрон IRT-3 или IRT-6 с блоком его запуска. Она предназначается для запуска системы коммутации разряда в заданный момент времени синхроимпульсом, выведенным на пульт управления SFR.

Система питания включает в себя модернизированный высоковольтный источник зарядных напряжений [9], предназначенный для автоматического заряда емкостного накопителя энергии $(C=0.4-2 \mu \mathrm{F})$, зарядное напряжение регулируется в пределах $\left(U_{0}=4-20 \mathrm{kV}\right)$.

Для проверки методики сверхскоростной фоторегистрации на цветные и многослойные спектрозональные пленки были исследованы два объекта: электрический разряд в режиме самопробоя разрядного промежутка в атмосфере [6] и электрический пробой в канале, образованном $\mathrm{EW}$, описываемый в настоящей работе.

На рис. 2, a приведена принципиальная оптико-кинематическая схема SFR-1 в варианте фоторегистратоpa. Входной объектив $O_{1}$ строит действительное изображение исследуемого самосветящегося объекта 1 в плоскости щелевой диафрагмы 2. Промежуточный объектив $\mathrm{O}_{2}$ изображает щель совместно с выделенной ею частью оптического изображения объекта на поверхности фотопленки. Вращающееся зеркало 7 обеспечивает непрерывное смещение изображения щели по светочувствительному слою пленки 10 с некоторой скоростью развертки $V_{\mathrm{r}}$. При равномерном вращении зеркала скорость движения изображения по пленке $V_{\mathrm{r}}=4 \pi n r$, где $r-$ радиус развертки, равный $239 \mathrm{~mm}$; $n$ - число оборотов зеркала в единицу времени. Например, $n=6 \cdot 10^{4} \mathrm{rpm} ; V_{\mathrm{r}}=3 \cdot 10^{3} \mathrm{~m} / \mathrm{s}$. По углу наклона фотограммы исследуемого объекта, полученной на пленке 10, можно определить скорость его перемещения вдоль щели по формуле $V_{\mathrm{ob}}=\left(V_{\mathrm{r}} / \beta\right) \cdot \operatorname{tg} \varphi$, где $V_{\mathrm{ob}}$ - скорость перемещения объекта вдоль щели; $\varphi-$ угол наклона касательной к кривой фотограммы; $\beta$ - поперечное увеличение фоторегистратора. Время экспозиции $t_{0}$ фоторегистратора определяется соотношением $t_{0}=l_{s}^{\prime} / V_{\mathrm{r}}$, где $l_{s}^{\prime}$ - ширина изображения щели на пленке. Временно́е разрешение при максимальной скорости развертки $\Delta t_{s}=0.5-0.7 / V_{\mathrm{r}} \approx 2 \cdot 10^{-8} \mathrm{~s}[2]$. Как правило, в процессе фотосьемки ширина щели берется равной $l_{s}=0.1 \mathrm{~mm}$. Скорость развертки фоторегистратора выбирается из условия $V_{\mathrm{r}} \geq\left(l_{s} V_{\mathrm{ob}}\right) / \Delta_{\mathrm{ad}}$, где $\Delta_{\mathrm{ad}}=$ $=0.03-0.05 \mathrm{~mm}-$ допустимая величина нерезкости изображения, получающаяся вследствие его смещения относительно светочувствительного слоя фотопленки. Пространственное разрешение фоторегистратора в направлении перемещения луча $N=1 / V_{\mathrm{r}} t_{0}=1 / l_{s}^{\prime}$ line $/ \mathrm{mm}$. Для $l_{s}^{\prime}=0.1 \mathrm{~mm}$, величина $N=1 / 0.1=10$ line $/ \mathrm{mm}$. Это
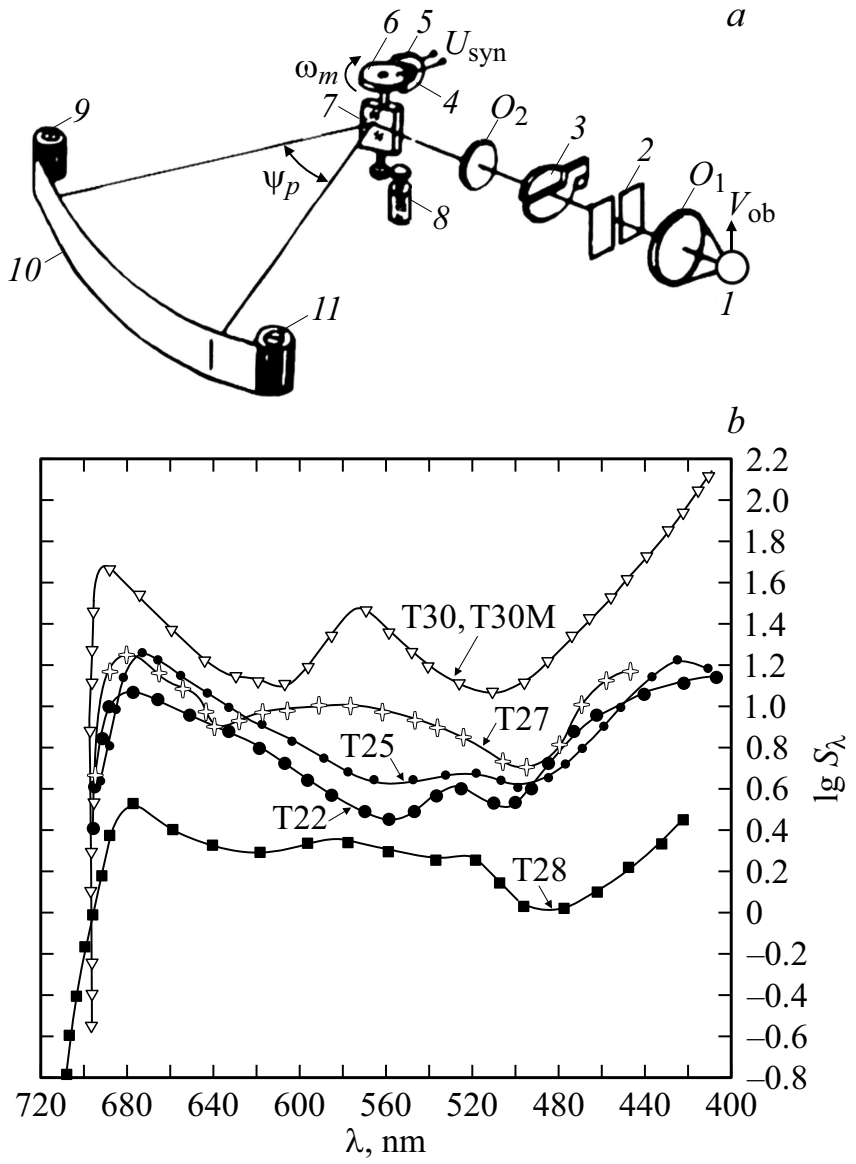

Рис. 2. Оптико-кинематическая схема SFR-1 в варианте фоторегистратора: 1 - исследуемый объект; $O_{1}-$ входной объектив; 2 - щель; 3 - затвор; $O_{2}-$ промежуточный объектив; 4 - железный штифт; 5 - катушка датчика; 6 - диск; 7 - зеркало; 8 - электромотор; 9, 11 - фотокассеты, 10 - фотопленка $(a)$; характеристики спектральной чувствительности черно-белых фотопленок: Аэрофото тип 22, тип 25 , тип 27 , тип 28 , тип $30(b)$.

динамическая разрешающая способность SFR в режиме фоторегистратора. Статическая разрешающая способность SFR (паспортное значение) составляет 18 line $/ \mathrm{mm}$. Скорость развертки в варианте фоторегистратора меняется от 150 до $3750 \mathrm{~m} / \mathrm{s}$ при скоростях вращения зеркала от 3000 до $75000 \mathrm{rpm}$. Для скорости развертки $3000 \mathrm{~m} / \mathrm{s}$ $(n=60000 \mathrm{rpm})$, используемой нами в процессе фоторегистрации, полное время регистрации $\Delta t=125 \mu \mathrm{s}$.

Рассмотрим работу системы синхронизации SFR c исследуемым явлением, которая использовалась в настоящей работе. Как известно [2], при вращении зеркала 7 в камере SFR в катушке датчика числа оборотов 5 наводится импульс напряжения $U_{s y n}$ в момент прохождения железного штифта 4 мимо сердечника датчика. Датчик может быть повернут вокруг оси зеркала и установлен в любом положении. Таким образом, импульс от датчика может быть получен в любом заданном положении зеркала при его вращении. При нажатии пусковой кнопки на пульте управления SFR реле замыкает свои 
нормально разомкнутые контакты с выдержкой времени, достаточной для того, чтобы затвор 3 успел полностью открыться. При замыкании контактов реле на сетку лампы $V_{3}$ типа $6 \mathrm{G} 8$ (принципиальная схема в паспорте SFR) попадут преобразованные импульсы датчика. Первый же импульс, прошедший после замыкания контактов реле, усилится лампами $V_{3}$ и $V_{4}$ и, попав на сетки тиратронов $V_{5}, V_{6}, V_{7}$, вызовет их зажигание. Запускающий импульс задается датчиком, устанавливаемым под требуемым углом относительно рабочего положения зеркала. При этом достигается согласование момента подачи инициирующего импульса с положением регистрируемого изображения на пленке 10. При зажигании тиратронов происходит разряд конденсаторов через первичную обмотку импульсного трансформатора. При этом во вторичной обмотке трансформатора индуктируется импульс высокого напряжения, который используется для инициирования исследуемого явления. При подключенном электрошнуре величина инициирующего высоковольтного импульса составляет величину $5-10 \mathrm{kV}$. Однако в настоящей работе использовалась система синхронизации, связанная с низковольтным импульсом порядка сотен вольт, возникающим на нагрузочном сопротивлении в общей цепи катода тиратронов $V_{5}, V_{6}, V_{7}$ типа TG-3-0.1/1.3. Импульс синхронизации, снимаемый с нагрузочного сопротивления через переходной конденсатор, подавался на выходной коаксиальный разъем, смонтированный на пульте управления SFR. Данная простая система синхронизации не предусмотрена в заводском варианте SFR и монтируется на пульте управления SFR дополнительно. Использование такой системы синхронизации показало ее высокую надежность и создает ряд удобств (возможность использования дополнительной задержки) при проведении ряда экспериментов.

\section{2. Сверхскоростная фотосъемка самосветящихся объектов с использованием специальных фотоматериалов}

На первом этапе в процессе юстировки при полностью открытой диафрагме в камере SFR производят перемещение исследуемого в эксперименте объекта вдоль оптической оси системы, добиваясь при этом четкого, сфокусированного изображения электродов, подсвеченных лампой накаливания, на матовом экране, который устанавливается на место пленки в SFR. По величине изображения измеряют масштаб фотосъемки. Вместо полностью открытой диафрагмы в камере SFR вводят щель, которая вырезает часть оптического изображения. При продольном перемещении щели добиваются ее четкого сфокусированного изображения на матовом экране. После этого матовый экран убирается и вместо него с левой стороны SFR вставляется кассета 9 с заряженной перфорированной пленкой шириной $35 \mathrm{~mm}$ и длиной около $1 \mathrm{~m}$. После установки светозащитного
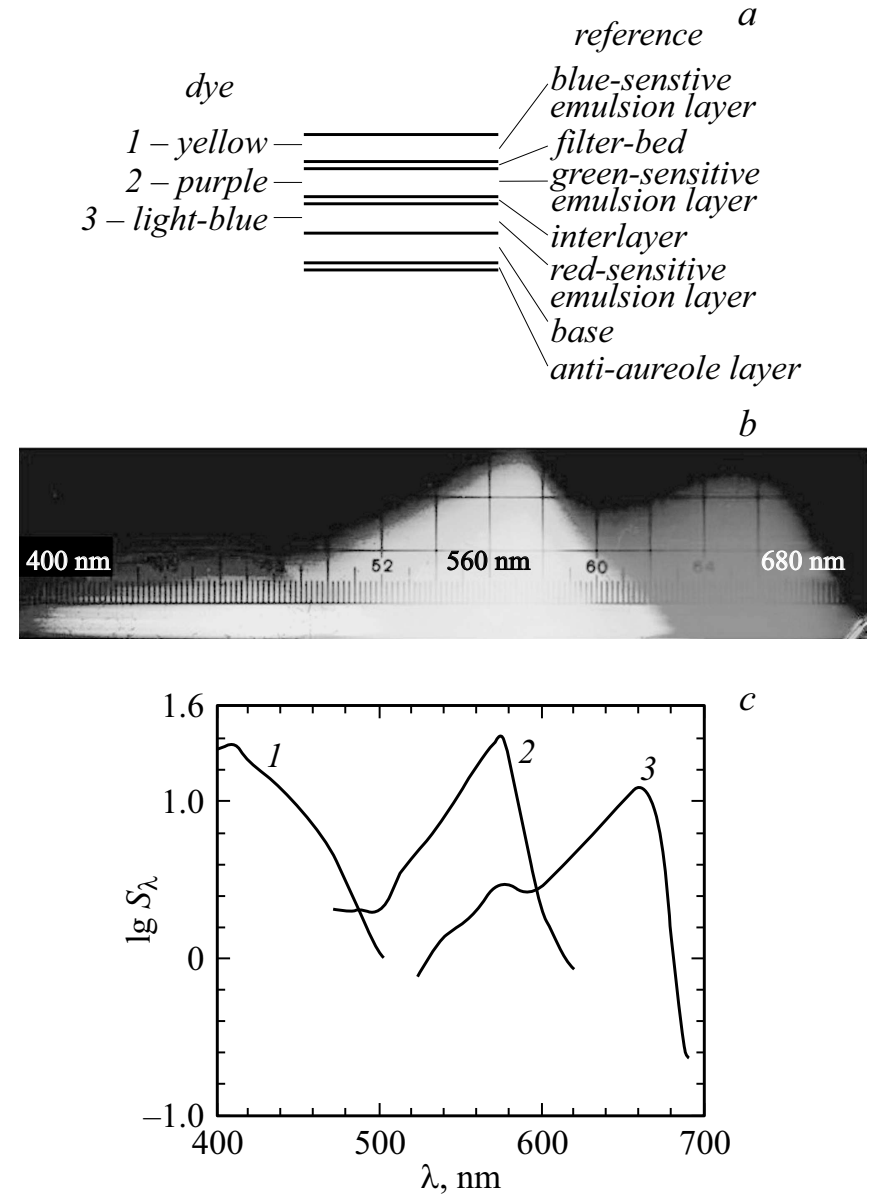

Рис. 3. Схема строения трехслойной цветной аэрофотопленки ЦN-4 - $(a)$; позитивное изображение спектрограммы трехслойной цветной негативной фотопленки типа ЦN-4 $(b)$; кривые распределения спектральной светочувствительности элементарных слоев аэрофотопленки ЦN-4: 1 - синечувствительный слой (желтый краситель), 2 - ортохроматический слой (пурпурный краситель), 3 - панхроматический слой (голубой краситель) $(c)$.

кожуха перед началом экспонирования производится перемотка пленки приемной кассетой на один кадр и ее прижим для фиксации в фокальной поверхности камеры. Для получения пробной фотограммы сначала экспонируется черно-белая пленка с областью сенсибилизации и чувствительностью, близкой или превышающей аналогичные параметры цветной негативной пленки ЦN-4, ЦN-5. Наиболее подходящими пленками являются Аэрофото тип 27 и Аэрофото тип 22, характеристики спектральной чувствительности которых приведены на рис. 2, $b$. При наличии заряженной черно-белой пленки в камере SFR, выставленном по электронному тахометру числе оборотов зеркала SFR и подключенном кабеле синхронизации с пульта управления производят экспонирование пленки излучением, возникающим при электрическом пробое. Далее производят отжим пленки и обратную ее перемотку на один кадр. Экспонированный кусок черно-белой пленки проявляется, закрепляется, 


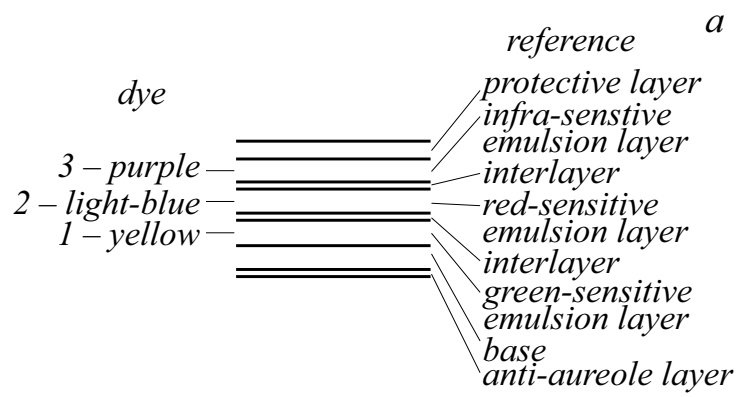

$b$
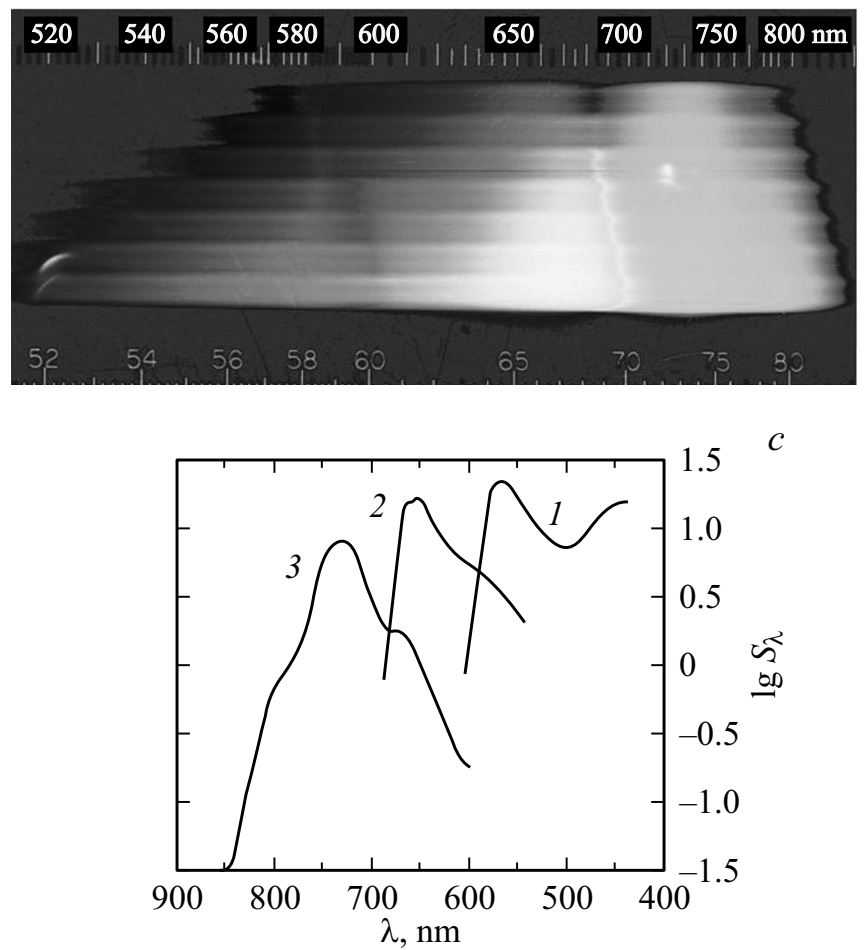

Pис. 4. Схема строения трехслойной цветной аэрофотопленки $\mathrm{SN}-15-(a)$; позитивное изображение спектрограмм трехслойной спектрозональной пленки типа $\mathrm{SN}-15-(b)$; кривая распределения спектральной светочувствительности элементарных слоев аэрофотопленки SN-15: 1 - ортохроматический слой (желтый краситель), 2 - панхроматический слой (голубой краситель), 3 - инфрахроматический слой (пурпурный краситель) (c).

производится его окончательная промывка и высушивание. По полученной фотограмме анализируется правильность установки датчика синхронизации SFR, так, чтобы начало изображения (фотограммы) находилось с правого конца экспонируемого участка пленки. Скорость вращения зеркала выбирается, так, чтобы средний угол наклона фотограммы был близок к $45^{\circ}$.

На следующем этапе для регистрации излучения исследуемого разряда в камеру SFR вставляется катушка с цветной негативной неперфорированной пленкой ЦN-4 или ЦN-5 шириной $35 \mathrm{~mm}$ и длиной около $1 \mathrm{~m}$, конец которой сшивается с любым куском засвеченной перфорированной пленки, который играет роль раккорда.
Следует отметить, что в SFR используется только перфорированная пленка шириной $35 \mathrm{~mm}$. Цветные аэрофотопленки такого формата не производятся. Строение и характеристики цветной негативной пленки ЦN-4 приведены на рис. 3. При ее экспонировании цветные фильтры ЖS-11, ЖS-12 [10] ставятся лишь при наличии сильного ультрафиолетового излучения в спектре исследуемого разряда. Для обеспечения оптимальной плотности красителей в полученном изображении при фотосъемке используют набор нейтральных светофильтров типа NS [10], которые спектрально не избирательны и ослабляют поток излучения источника в заданное число раз. Однако при использовании спектрозональной негативной пленки SN-15 установка желтого ЖS-18 или
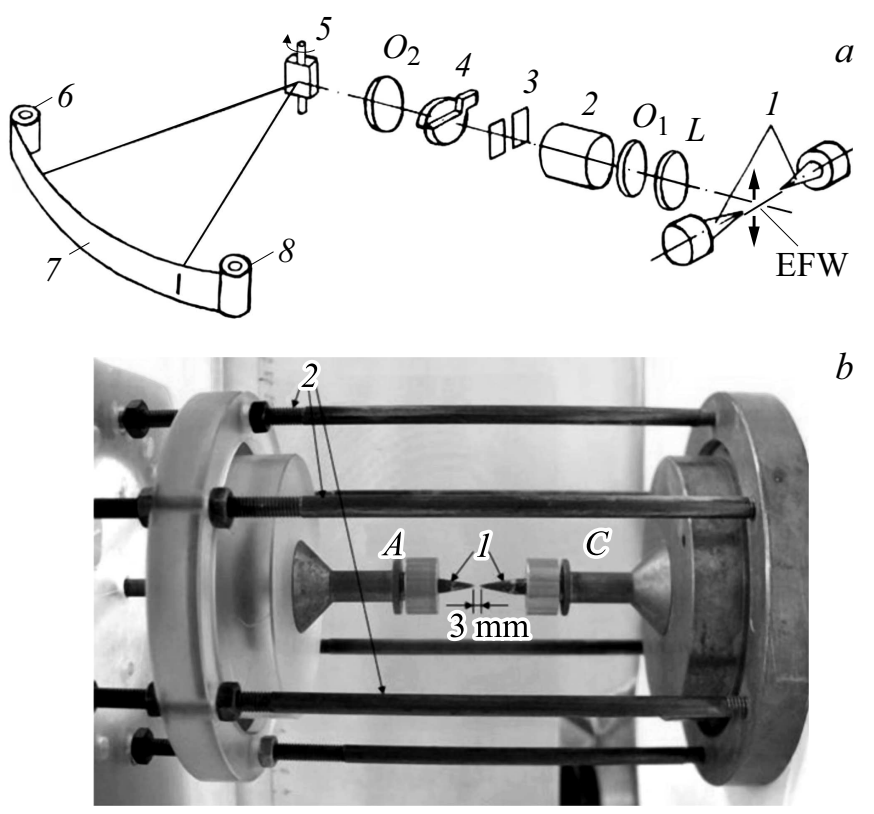

$b$

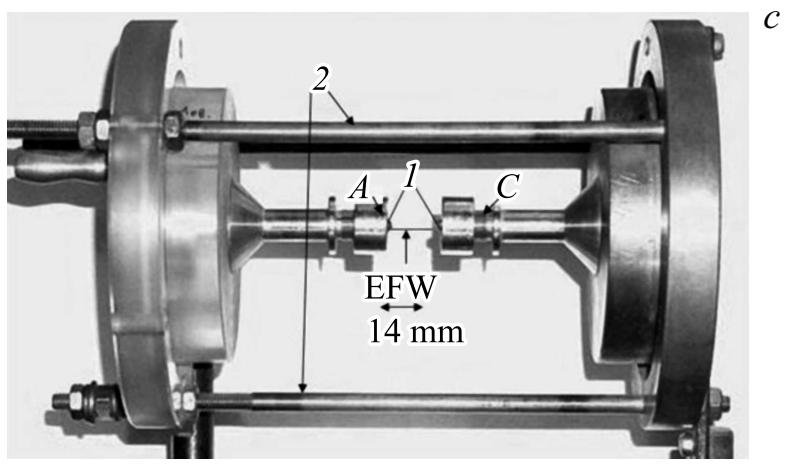

Рис. 5. Оптическая схема фоторегистрации: 1 - молибденовые электроды; EFW - взрывающаяся тонкая проволока; $L-$ дополнительная линза; $O_{1}-$ входной объектив; 2 - переходное кольцо; 3 - щель; 4 - затвор; $O_{2}-$ промежуточный объектив; 5 - зеркало; 6,8 - фотокассеты; 7 - фотопленка $(a)$; фото камеры с разрядным промежутком: 1 - молибденовые электроды; 2 - обратный токопровод; $A-$ анод; $C-$ катод $(b)$; фото камеры для взрыва проволоки: 1 - цанговые зажимы из латуни; 2 - обратный токопровод; EFW - взрывающаяся тонкая проволока; $A-$ анод; $C-$ катод $(c)$. 
оранжевого светофильтра OS-17, OS-14 [10] обязательна. Строение и характеристики пленки $\mathrm{SN}-15$ приведены на рис. 4. В этом случае фильтр задерживает излучение синей части спектра, к которому чувствительны все слои пленки. Выбор конкретного типа светофильтра подбирается индивидуально в каждом эксперименте. После каждого экспонирования в незасвеченный кусок пленки впечатывается на сенситометре ЦS-2M ступенчатый оптический клин. Практика использования пленок показала, что ширина щели $l_{s}=0.1 \mathrm{~mm}$ SFR обеспечивает достаточную плотность красителя при экспонировании на цветные и спектрозональные пленки источника с цветовыми температурами, превышающими $2500 \mathrm{~K}$ при скорости вращения зеркала SFR $n=60000 \mathrm{rpm}$. При фоторегистрации электрического пробоя в атмосфере предпочтение отдается трехслойной спектрозональной пленке SN-15 (три зоны спектра). Двуслойные спектрозональные пленки типа SN-6M, SN-10 (две зоны спектра), аналогичные пленкам KODAK Color Infrared Aerial Film [5], использовались в настоящей работе значительно реже.

\section{3. Фоторегистрация электрического пробоя в канале искрового разряда и в канале, образованном взрывом проволоки}

На рис. 5, $a$ представлена оптическая схема фоторегистрации пространственно-временного развития канала искрового разряда, описанного в работе [6], и разряда, инициированного взрывом тонкой проволоки EFW. В стандартную схему фоторегистратора SFR-1 $[1,2]$ внесены следующие изменения. Штатный объектив регистратора $O_{1}$ крепится к переходному кольцу 2 . В качестве промежуточного объектива $O_{2}$ в фоторегистраторе использован объектив И-23. Для получения заданного масштаба изображения при приемлемой в нашем эксперименте длине переходного кольца $(L \sim 90 \mathrm{~mm})$ использовалась дополнительная длиннофокусная линза $L$ (фокусное расстояние $f \sim 0.5 \mathrm{~m}$ ). Эта схема позволяет получать без существенных оптических искажений изображение исследуемого разряда в масштабе $1: 1.15$.

При исследовании электрического пробоя разряд инициировался между двумя молибденовыми электродами конической формы 1 , так как показано на рис. $5, b$. Стрелками указано регистрируемое направление расширения канала разряда в плоскости симметрии разрядного промежутка. Длина разрядного промежутка $l_{0} \approx 3 \mathrm{~mm}$. Для облегчения режима самопробоя разрядного промежутка при $U_{0} \approx 10 \mathrm{kV}$ параллельно электродам 1 постоянно подключалось сопротивление величиной $3 \mathrm{M} \Omega$.

При исследовании разряда, инициированного взрывом проволоки, молибденовые электроды убирались, и вместо них вставлялся отрезок тонкой проволоки (EFW), закрепленной между двумя цанговыми зажимами 1 , так, как показано на рис. 5,c. Стрелками указано регистрируемое направление расширения канала разряда
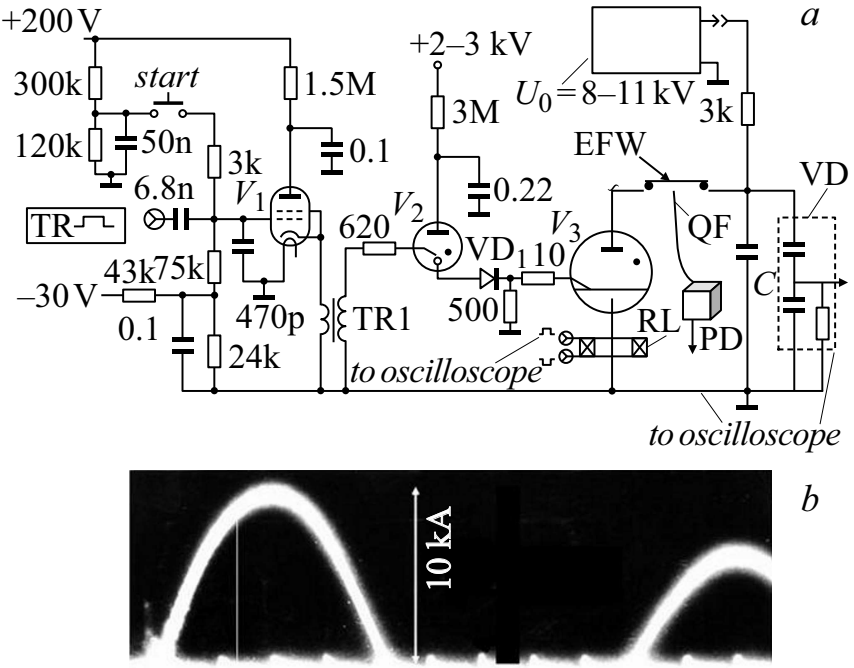

$b$
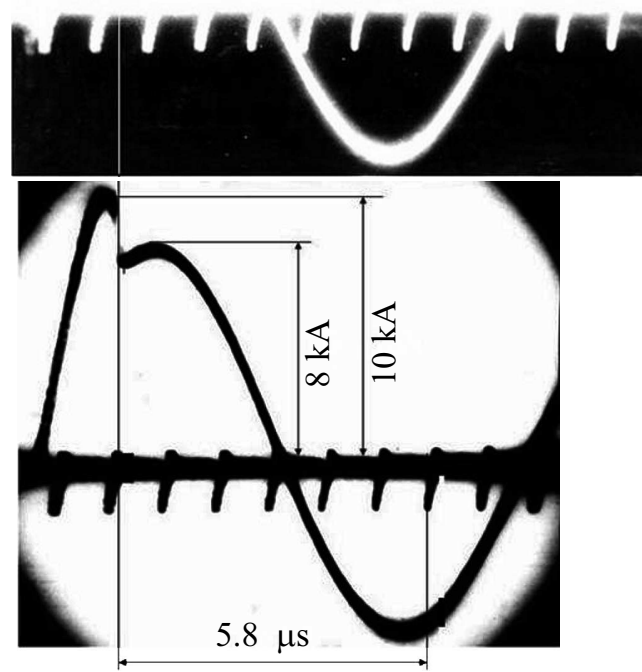

$c$

Рис. 6. Схема эксперимента по инициированию пробоя в канале проволоки: $V_{1}-\mathrm{TG}-1-3 / 1 ; V_{2}-$ VIR-14; $V_{3}-$ IRT-3; $\mathrm{VD}_{1}$-KD206; RL — пояс Роговского; VD - делитель напряжения; TR - пусковой импульс; EFW - взрывающаяся тонкая проволока; PD - фотодиод; QF - кварцевое волокно $(a)$; осциллограмма тока пробоя разрядного промежутка $3 \mathrm{~mm}$, метки времени $1 \mu \mathrm{s}(b)$; осциллограмма тока взрывающейся проволоки $\varnothing 150 \mu \mathrm{m}, L=15 \mathrm{~mm}$, метки времени $1 \mu \mathrm{s}(c)$. Параметры разряда $U_{0}=10 \mathrm{kV}, C=2 \mu \mathrm{F}$.

в плоскости симметрии разрядного промежутка. Длина разрядного промежутка $L \approx 15 \mathrm{~mm}$. Для инициирования электрического пробоя в атмосфере был использован горизонтально ориентированный проводник из меди марки PEV-2, длина и диаметр которого составляли: $L=14-15 \mathrm{~mm}, \varnothing 90-150 \mu \mathrm{m}$ при зарядном напряжении $U_{0}=10-11 \mathrm{kV}$ и емкости $C=2 \mu \mathrm{F}$. Проводились также эксперименты по инициированию пробоя с помощью проводника из $\mathrm{NiCr}$ с $L=14-15 \mathrm{~mm}, \varnothing 100 \mu$ m при тех же параметрах разрядной цепи.

На рис. $6, a$ представлена схема коммутации разряда и положение датчиков для измерения тока поясом Роговского RL, напряжения на конденсаторной батарее c 
помощью делителя напряжения VD и положение торца полированного кварцевого волокна QF, передающее излучение из канала разряда на быстродействующий ріп фотодиод $\mathrm{PD}$ с временным разрешением $\sim 1$ ns. В разрядном промежутке находится отрезок тонкой проволоки EFW. В качестве коммутирующего элемента $V_{3}$ использовались игнитроны IRT-3, IRT-6, обеспечивающие скорость нарастания разрядного тока $10 \mathrm{kA} / \mu \mathrm{s}$. Измерение формы импульса тока производилось с помощью дифференциального экранированного пояса Роговского с временным разрешением $\sim 30 \mathrm{~ns}$ и постоянной интегрирования $\theta=L_{\Sigma} / 2 R \approx 380 \mu \mathrm{s}$ [6]. Измерение формы напряжения на разрядном промежутке производилось с помощью экранированного VD смешанного типа, подключенного к аноду батареи конденсаторов. Данный делитель напряжения дает ошибку измерения $~ 1 \%$ при длительности фронта тока $\tau_{f} \geq 1 \mu \mathrm{s}$ [11]. Достоинством данного делителя является то, что он не шунтирует слаботочный источник зарядных напряжений. В качестве регистрирующего прибора в работе использовался цифровой осциллограф Tektronix TDS 220 и аналоговый осциллограф C9-4A. Конденсатор (емкостью $C=2 \mu \mathrm{F}$ ) заряжался от источника зарядных напряжений до значения $U_{0}=8-11 \mathrm{kV}$.

На рис. 6, $b$ приведена форма тока при пробое разрядного промежутка $l_{0} \approx 3 \mathrm{~mm}$, зарегистрирована на аналоговом осциллографе C9-4A с метками времени $1 \mu \mathrm{s}$. Она имеет вид затухающей синусоиды, что характерно для такого типа электрического пробоя, сопровождаемого сильноточной импульсной дугой на переменном токе. Начальная скорость нарастания тока $F=(d J / d t)_{t=0} \approx 8 \cdot 10^{9} \mathrm{~A} / \mathrm{s}$. Декремент затухания равен $\Delta=1.52$.

При наличии в разрядном промежутке отрезка тонкой проволоки (EFW) характер поведения тока в его начальной стадии резко меняется. Это связано с физическими процессами, происходящими при $\mathrm{EW}$ в его начальной стадии $[12,13]$. Начальная скорость нарастания тока в этом случае $F=(d J / d t)_{t=0} \approx 10^{10} \mathrm{~A} / \mathrm{s}$. Особенностью $\mathrm{EW}$ из меди $\varnothing 150 \mu \mathrm{m}, L \approx 15 \mathrm{~mm}$ является наличие провала на осциллограмме тока EW, так, как показано на pис. $6, c$. Положение провала тока на осциллограмме зависит от материала и диаметра проволоки. В литературе это явление называют „паузой тока“ $[14,15]$, которая характеризуется резким увеличением сопротивления электрической цепи при EW в его начальной стадии. В отличие от взрывающихся проводников, длина которых превышает десятки сантиметров [16,17], при EW коротких проводников из меди и $\mathrm{NiCr}(\varnothing 100-150 \mu \mathrm{m}, L \approx 15 \mathrm{~mm})$ провал на осциллограмме тока происходит не до нуля и пауза тока практически отсутствует. Сразу же после провала тока происходит электрический пробой в парах EW. На рис. 6, $c$ указан также типичный интервал времени $\Delta t \sim 5.8 \mu$ s начала образования вторичной ударной волны в плазме, механизм формирования которой будет рассмотрен далее.

На рис. 7, $a$ приведена форма тока при электрическом пробое разрядного промежутка $l_{0} \approx 3 \mathrm{~mm}$, зарегистри-
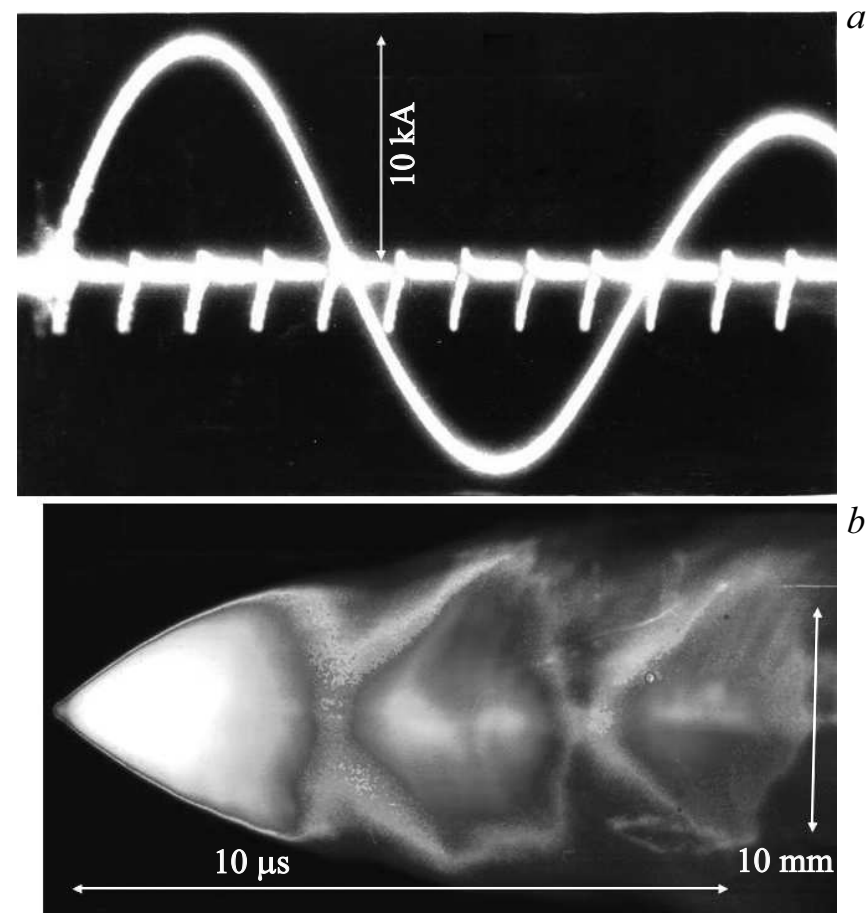

Рис. 7. Осциллограмма тока пробоя разрядного промежутка $3 \mathrm{~mm}$, аналоговые метки времени $1 \mu \mathrm{s}(a)$; фотограмма пробоя на цветной спектрозональной пленке $\mathrm{SN}-15$, светофильтр OS-17 (b). Скорость развертки $3 \cdot 10^{3} \mathrm{~m} / \mathrm{s}$. Масштаб фотосъемки $1: 1.15$. Параметры разряда $U_{0}=10 \mathrm{kV}, C=2 \mu \mathrm{F}$.

рованная на аналоговом осциллографе С9-4А с метками времени $1 \mu \mathrm{s}$. На рис. 7, $b$ приведена фотограмма пробоя с привязкой во времени к форме тока, которая регистрировалась на спектрозональной пленке типа $\mathrm{SN}-15$, экспонируемой за оранжевым фильтром OS-17. Емкость накопителя $C=2 \mu \mathrm{F}, U_{0}=10 \mathrm{kV}$. Скорость развертки составляла $3 \cdot 10^{3} \mathrm{~m} / \mathrm{s}$. Масштаб фотосъемки $1: 1.15$. На фотограмме, начиная с момента пробоя, отдельные максимумы свечения разряда во времени соответствуют максимальным значениям полупериода тока разрядной цепи. Первичная ударная волна, порождаемая тепловой зоной разряда в первом полупериоде тока не видна, так как ее интенсивности и скорости движения недостаточно, чтобы вызвать сильное свечение атмосферы. Для ее визуализации в работах $[18,19]$ используют оптические схемы, требующие внешнего источника подсветки (отражающего зеркала, установленного за исследуемым объектом). В отличие от черно-белой фоторегистрации фотограмма на спектрозональной пленке SN-15 получается цветной за счет различия цветовых температур различных областей разряда. При этом в развивающейся центральной части разряда (токовой зоне) регистрируется микроструктура плазменного облака, обусловленная мелкомасштабными перегревными неустойчивостями [20] и поступлением в результате эрозии паров вещества электродов в плазму. В начале второго полупериода $\left(t_{2} \sim 4 \mu \mathrm{s}\right)$ и третьего полупериода $\left(t_{3} \sim 9 \mu \mathrm{s}\right)$ разрядного тока видны ударные волны, скорость которых 


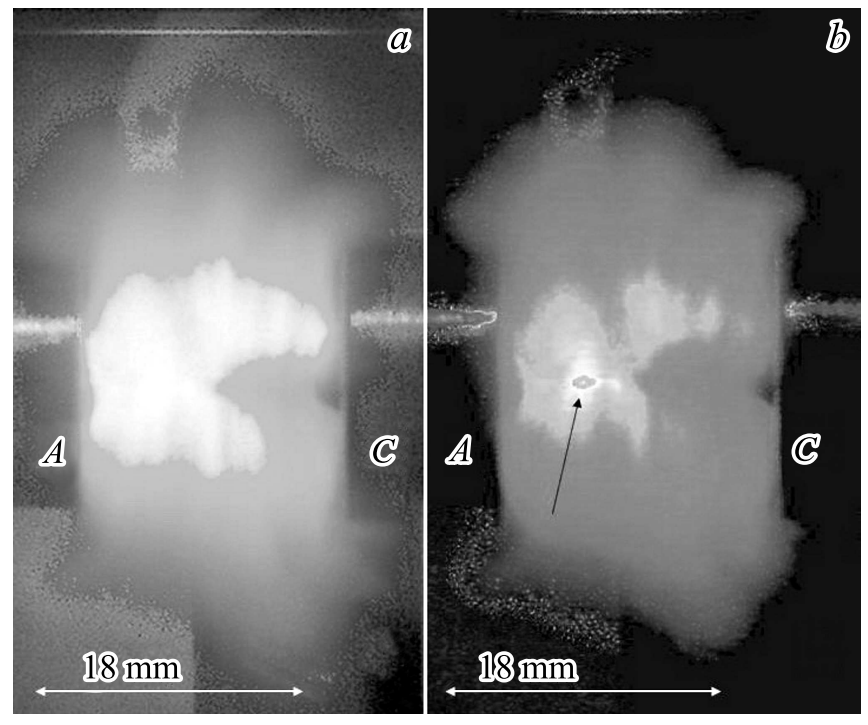

Рис. 8. Интегральное фото взрыва проволоки из меди $\varnothing 150 \mu \mathrm{m}, L=15 \mathrm{~mm}(a)$; обработка изображения в системе цифровых координат $\mathrm{HSB}(b)$. Параметры разряда $U_{0}=10 \mathrm{kV}$, $C=2 \mu \mathrm{F}$.

составляла $\sim 2600 \mathrm{~m} / \mathrm{s}$. Достаточно резкий фронт ударной волны имеет форму, близкую к прямой линии, что говорит об интенсивном энергетическом обмене между ударной волной и окружающей ее плазмой.

Прежде чем приступить к результатам по скоростной фоторегистрации пробоя в парах $\mathrm{EW}$ из меди и $\mathrm{NiCr}(\varnothing 100-150 \mu \mathrm{m}, L \approx 15 \mathrm{~mm})$, рассмотрим возможности цветной фотосъемки с помощью цифровой камеры. На рис. 8, a приведено интегральное фото $\mathrm{EW}$ из меди $\varnothing 150 \mu \mathrm{m}, L \approx 15 \mathrm{~mm}$, полученное путем фотосъемки через зеленый фильтр совместно с двумя нейтральными фильтрами NS-9 с помощью цифровой камеры OLYMPUS C-5050ZOOM. Емкость накопителя $C=2 \mu \mathrm{F}, U_{0}=10 \mathrm{kV}$. Методика фотосъемки описана в работах $[16,17]$. На фото (рис. $8, b$ ) видна особенность (указанная стрелкой) в центральной части в виде „горячей точки“ с размером $\Delta r \sim 0.5 \mathrm{~mm}$, яркость которой значительно превосходит окружающее ее плазменное образование. Этих точек может быть несколько, отдельных или вытянутых в линию на оси разряда. Следует отметить, что данное образование было выявлено на фото благодаря двум причинам. Первая из которых является свойством исследуемого объекта - плазма, образованная EW из меди, в данном эксперименте является полупрозрачным объектом в видимом диапазоне длин волн, включая ближнюю IR-область. Объект фотосъемки („горячая точка“) в силу особенностей конструкции был локализован в области симметрии разряда. Вторая причина заключается в том, что фото в цифровом формате можно обрабатывать в системе цифровых координат, например в HSB, так, как показано на рис. 8, $b$. Чем обусловлено данное образование и каков его механизм формирования? Это и следует выяснить в настоящей работе.
Для случая пробоя в парах $\mathrm{EW}$ из $\mathrm{NiCr} \varnothing 100 \mu \mathrm{m}$, $L \approx 15 \mathrm{~mm}$ при $C=2 \mu \mathrm{F}, U_{0}=10 \mathrm{kV}$ характер излучения исследуемого объекта существенно меняется. Плазма, образованная $\mathrm{EW}$ из $\mathrm{NiCr}$, является непрозрачным объектом в видимом диапазоне длин волн. Выявить какие-либо особенности внутри плазмы путем интегральной фотосъемки при использовании системы фильтров и обработке в цифровом формате не удалось.

В качестве иллюстрации метода интегральной фотосъемки на рис. 9, $a$ приведено типичное фото пробоя в парах $\mathrm{EW}$ из меди $\varnothing 150 \mu \mathrm{m}, L \approx 15 \mathrm{~mm}$ при $C=2 \mu \mathrm{F}$ и $U_{0}=10 \mathrm{kV}$. Соответствующий результат цифровой обработки приведен на рис. $9, b$.

Дальнейшие исследования методом сверхскоростной фоторегистрации $\mathrm{EW}$ из меди и $\mathrm{NiCr}$ показало, что имеется ряд интересных явлений, сопутствующих процессу $\mathrm{EW}$ и электрическому пробою в парах проволоки. Одно из них - это образование вторичной ударной волны в плазме на втором полупериоде разрядного тока. Данное явление было зарегистрировано автором в ходе экспериментов, описанных в работе [6] в 1986 г. До настоящего времени результаты этих исследований не были опубликованы, так как физика процесса образования такой ударной волны при максимальном разрядном токе $I_{\max } \sim 10 \mathrm{kA}$ мало понятна и до настоящего времени до конца не исследована.

На рис. $10, a, b$ приведены осциллограммы тока и излучения $\mathrm{EW}$ из меди $\varnothing 150 \mu \mathrm{m}, L \approx 15 \mathrm{~mm}$, зарегистрированная на цифровом осциллографе Tektronix TDS 220 при $C=2 \mu \mathrm{F}, U_{0}=10 \mathrm{kV}$. Следует отметить, что регистрируемое pin фотодиодом излучение в видимом и ближнем IR-диапазонах начинается с момента про-

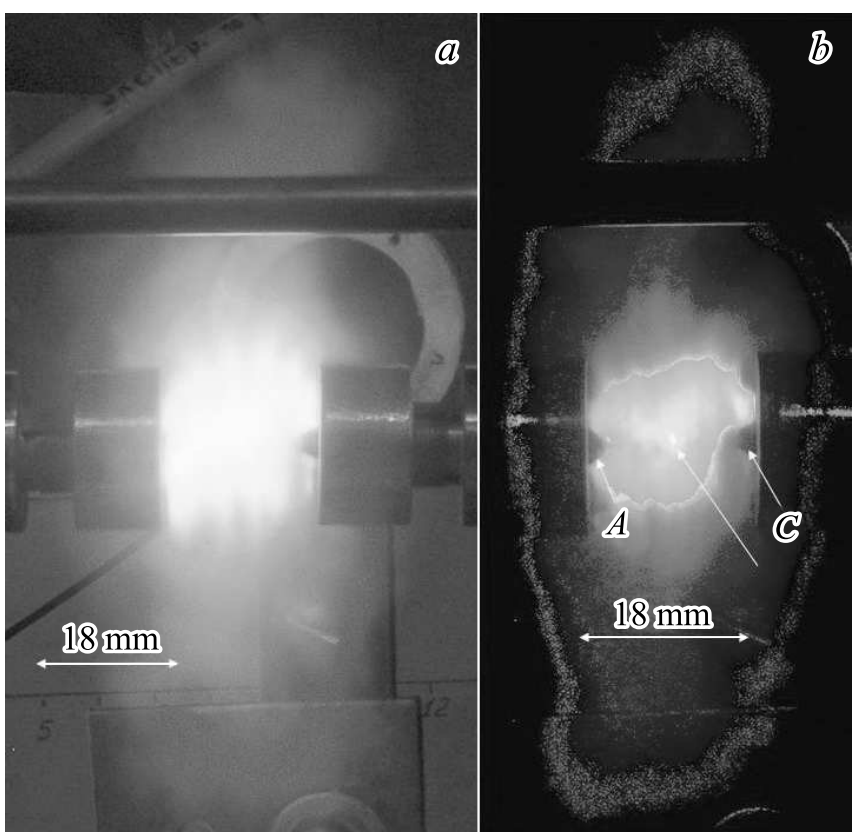

Рис. 9. Интегральное фото взрыва проволоки из меди $\varnothing 150 \mu \mathrm{m}, L=15 \mathrm{~mm}(a)$; обработка изображения в системе цифровых координат $\operatorname{HSB}(b)$. Параметры разряда $U_{0}=10 \mathrm{kV}$, $C=2 \mu \mathrm{F}$ 

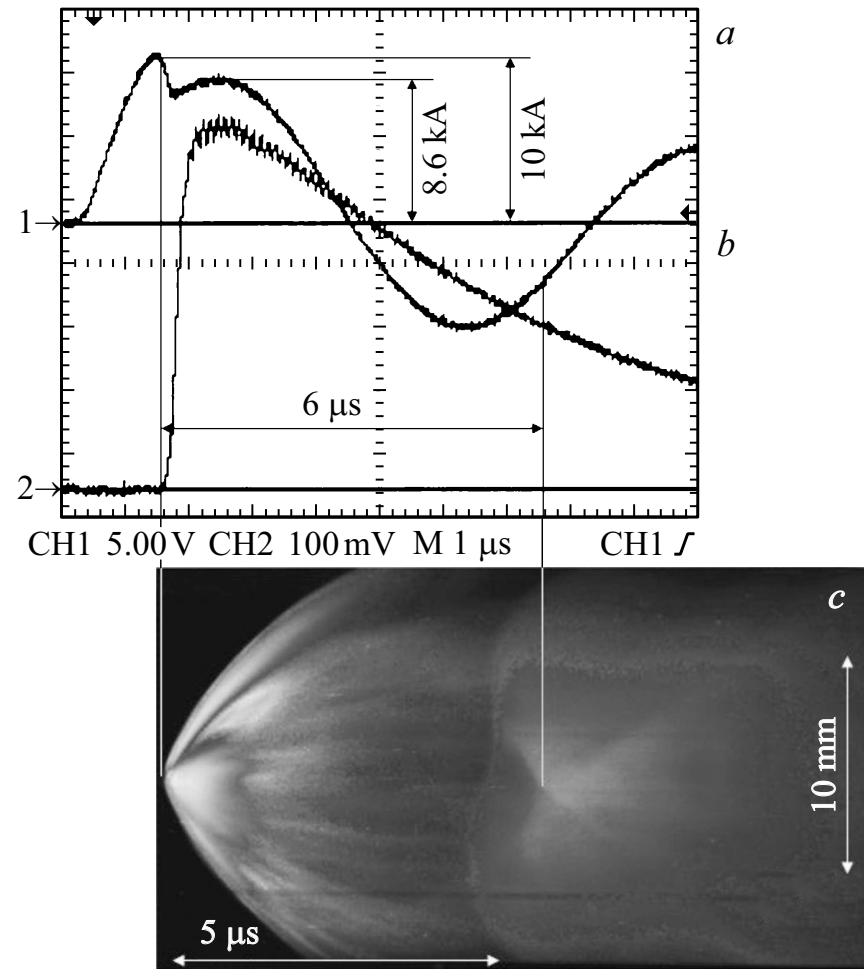

Рис. 10. Осциллограммы тока взрывающейся проволоки из меди $\varnothing 150 \mu \mathrm{m}, L=15 \mathrm{~mm}(a)$, свечения разрядного канала $(b)$; фотограмма пробоя на цветной спектрозональной пленке $\mathrm{SN}-15$, светофильтр OS-17 (c). Скорость развертки $3 \cdot 10^{3} \mathrm{~m} / \mathrm{s}$. Масштаб фотосъемки $1: 1.15$. Параметры разряда $U_{0}=10 \mathrm{kV}$, $C=2 \mu \mathrm{F}$.

вала на осциллограмме тока. До этого момента регистрируется излучение только в среднем IR-диапазоне 3-5 $\mu \mathrm{m}$ [21]. Особенностью EW-коротких проводников из меди и нихрома является наличие „темной“ фазы в механизме излучения в видимой и ближней IR-области до момента электрического пробоя (провала тока), когда среда EW увеличивала свою внутреннюю энергию в основном за счет увеличения давления до величины $\sim 500$ kbar. Следует отметить, что мгновенному разлету проволоки в жидком перегретом состоянии в этот период препятствуют силы инерции. Для меди $\varnothing 150 \mu \mathrm{m}, L \approx 15 \mathrm{~mm}$ необходимо давление $\sim 200 \mathrm{kbar}$, чтобы продукты взрыва проволоки двигались со скоростью не меньшей чем $\sim 1000 \mathrm{~m} / \mathrm{s}$. Из рис. $10, a, b$ следует, что начало во времени фотограмм, приведенных далее, соответствует моменту провала тока (электрическому пробою), так как пленка регистрирует излучение только в видимом и ближнем IR-диапазоне. На рис. 10, с приведена фотограмма пробоя в парах $\mathrm{EW}$ из меди $\varnothing 150 \mu \mathrm{m}, L \approx 15 \mathrm{~mm}, C=2 \mu \mathrm{F}, U_{0}=10 \mathrm{kV}$, которая регистрировалась на спектрозональную пленку типа SN-15 за оранжевым фильтром OS-17. Скорость развертки составляла $3 \cdot 10^{3} \mathrm{~m} / \mathrm{s}$. Масштаб фотосъемки $1: 1.15$. Начиная с момента пробоя, первичная ударная волна не видна, так как ее интенсивности и скорости движения недостаточно, чтобы вызвать сильное свечение атмосферы. Как уже отмечалось, для визуализации ударной волны в процессе фотосъемки используют оптические схемы с установкой отражающего зеркала за исследуемым объектом. Фотограмма на спектрозональной пленке типа SN-15, как и в случае обычного электрического пробоя в атмосфере, получается цветной, так как данный объект может быть описан моделью локального термодинамического равновесия. Наиболее интересной деталью в полученном изображении является наличие в процессе кумуляции „горячей точки“ на оси разряда в плоскости его симметрии. Данное явление наблюдается не постоянно и для случая EW из меди $\varnothing 150 \mu \mathrm{m}, L \approx 15 \mathrm{~mm}, C=2 \mu \mathrm{F}, U_{0}=10 \mathrm{kV}$ возникает по времени в области второго максимума тока. Положение „горячей точки“ может незначительно отклоняться на величину $\sim 3 \mathrm{~mm}$ от оси разрядного промежутка. Процесс кумуляции в плазме очень схож в своей динамике с явлением $z$-pinch, который использовался для импульсного нагрева плазмы электрическим током в работах И.В. Курчатова и Л.А. Арцимовича [22-24]. За фазой сжатия на фотограмме следует фаза расширения плазмы, граница которой визуализируется в виде вторичной ударной волны, движущейся на начальном этапе прямолинейно со скоростью $\sim 2000 \mathrm{~m} / \mathrm{s}$. Образование ударной волны в плазме произошло за счет внутренней

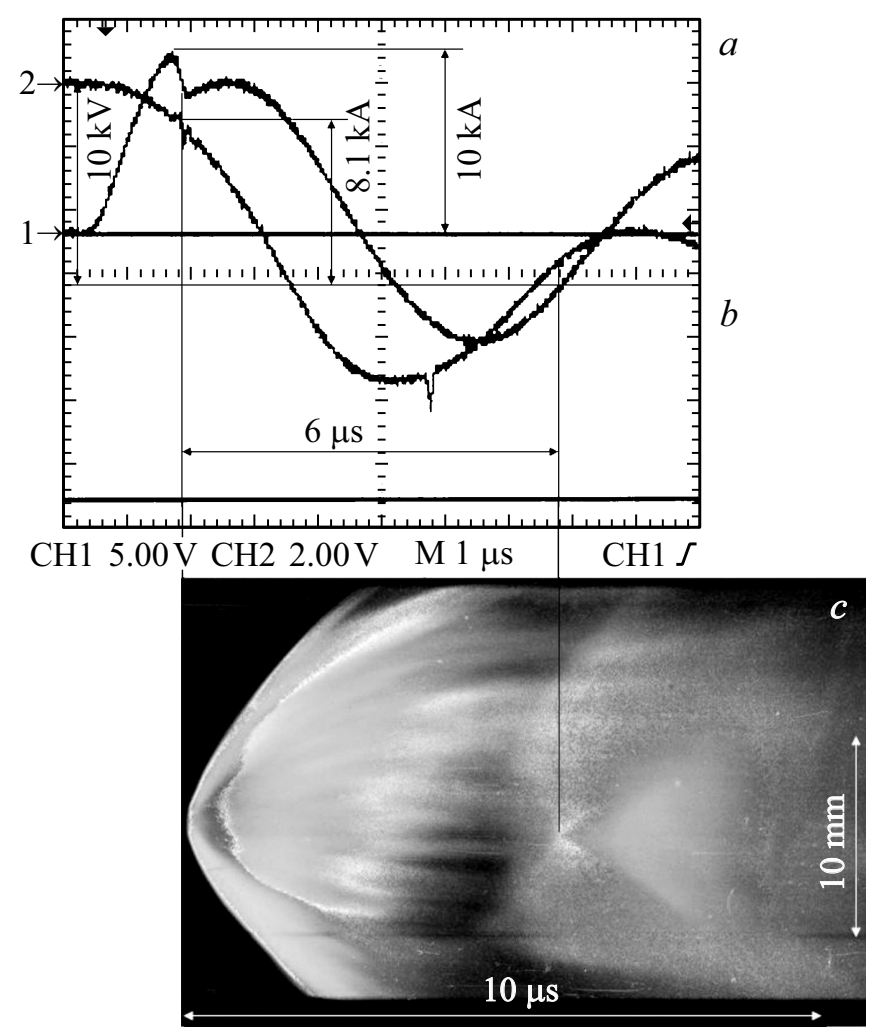

Рис. 11. Осциллограммы напряжения $(a)$, тока взрывающейся проволоки из меди $\varnothing 150 \mu \mathrm{m}, L=15 \mathrm{~mm}(b)$; фотограмма пробоя на цветной спектрозональной пленке $\mathrm{SN}-15$, светофильтр OS-17 (c). Скорость развертки $3 \cdot 10^{3} \mathrm{~m} / \mathrm{s}$. Масштаб фотосъемки $1: 1.15$. Параметры разряда $U_{0}=10 \mathrm{kV}, C=2 \mu \mathrm{F}$. 


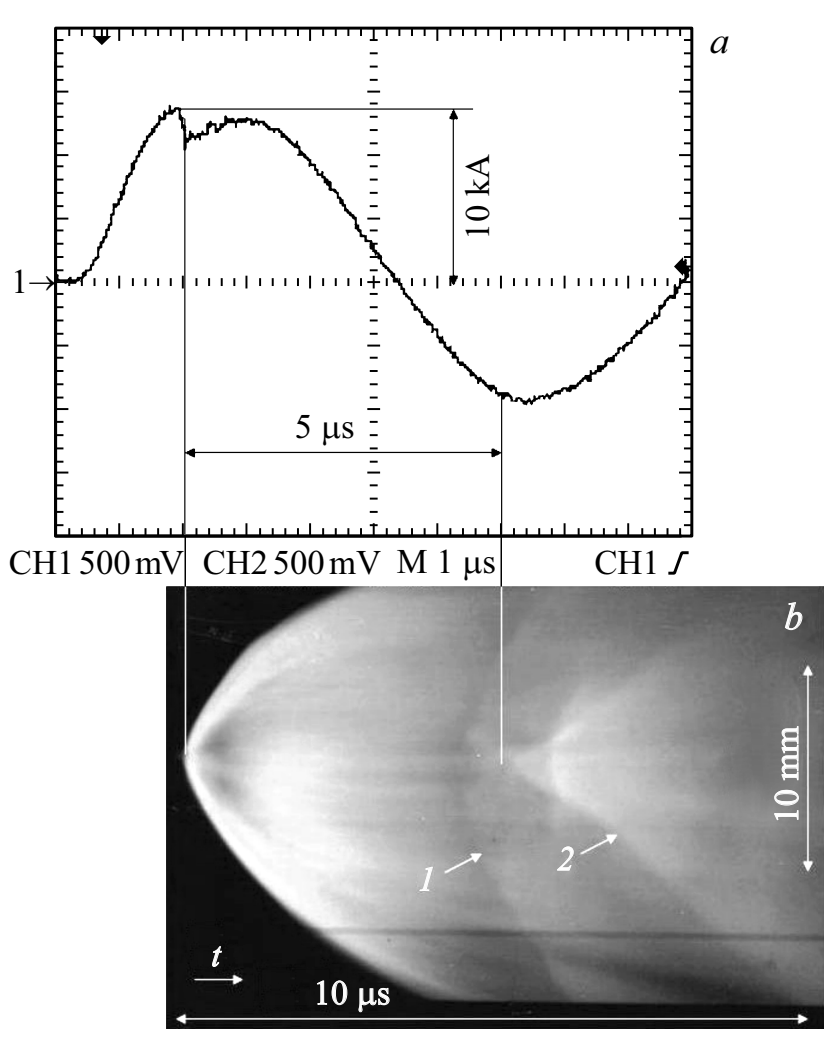

Рис. 12. Осциллограмма тока взрывающейся проволоки из меди $\varnothing 150 \mu \mathrm{m}, L=15 \mathrm{~mm}(a)$; фотограмма пробоя на цветной спектрозональной пленке SN-10, светофильтр OS-17 (b). Скорость развертки $3 \cdot 10^{3} \mathrm{~m} / \mathrm{s}$. Масштаб фотосъемки $1: 1.15$. Параметры разряда $U_{0}=10 \mathrm{kV}, C=2 \mu \mathrm{F}$.

энергии, накопленной в процессе кумуляции в области с размерами $\Delta r \sim 0.5 \mathrm{~mm}$ в момент максимального сжатия при образовании „горячей точки“ с высокой температурой и давлением. Перед началом процесса кумуляции на фотограмме видна „воронка“, внутренняя часть которой в виде ударной волны сходится к оси разряда со скоростью $\sim 4000 \mathrm{~m} / \mathrm{s}$, а наружная движется с такой же скоростью к его границе.

На рис. 11, $a, b$ представлена осциллограмма напряжения и тока $\mathrm{EW}$ из меди ф $150 \mu \mathrm{m}, L=15 \mathrm{~mm}, C=2 \mu \mathrm{F}$, $U_{0}=10 \mathrm{kV}$, зарегистрированная на цифровом осциллографе Tektronix TDS 220. Фотограмма пробоя на рис. $11, c$ регистрировалась на спектрозональной пленке типа SN-15 за оранжевым фильтром OS-17. Скорость развертки составляла $3 \cdot 10^{3} \mathrm{~m} / \mathrm{s}$. Масштаб фотосъемки $1: 1.15$. В полученном изображении также регистрируется „горячая точка“ на оси разряда с размером $\Delta r \sim 0.5 \mathrm{~mm}$, которая далее трансформируется в расходящуюся ударную волну с фронтом, близким к прямой линии в начале движения. Перед началом процесса кумуляции на фотограмме видна „воронка“, внутренняя часть которой в виде ударной волны сходится к оси разряда.

На рис. 12, а представлена осциллограмма тока EW из меди $\varnothing 150 \mu \mathrm{m}, L=15 \mathrm{~mm}, C=2 \mu \mathrm{F}, U_{0}=10 \mathrm{kV}$, за- регистрированная на цифровом осциллографе Tektronix TDS 220. Фотограмма пробоя на рис. $12, b$ регистрировалась на двуслойной спектрозональной пленке типа SN-10 за оранжевым фильтром OS-17. Данный тип пленки имеет только красночувствительный и инфрачувствительный эмульсионные слои точно так же как пленка фирмы KODAK Color Infrared Aerial Film. Особенность полученного изображения на фотограмме заключается в том, что процесс образования „горячей точки“ на оси разряда носит неустойчивый характер. Область ее локализации размыта и имеет размер $\Delta r>0.5 \mathrm{~mm}$. Перед областью формирования „горячей точки“ в плазме распространяется быстрая ударная волна 1 со скоростью $\sim 10^{4} \mathrm{~m} / \mathrm{s}$. Через интервал $\Delta t \sim 0.5 \mu \mathrm{s}$ от „горячей точки“ распространяется медленная ударная волна 2 со скоростью $\sim 1.8 \cdot 10^{3} \mathrm{~m} / \mathrm{s}$, фронт которой прямолинейный в начале движения. Время формирования кумуляции от начала пробоя в этом случае $\sim 5 \mu \mathrm{s}$.

Анализ опубликованных ранее работ показал, что аналогичный результат фоторегистрации вторичной ударной волны в плазме EW из меди $\varnothing 6.3 \mathrm{mil}(157.5 \mu \mathrm{m})$, $l_{0} \approx 20 \mathrm{~mm}$ при запасенной энергии $118 \mathrm{~J}$ был получен в работах F.D. Bennett's [18,19]. Параметры разрядной цепи $C=0.3 \mu \mathrm{F}, L=1 / 3 \mu \mathrm{H}, T=2 \mu \mathrm{s}, U_{0}=28 \mathrm{kV}$ существенно отличались от значений, приведенных в настоящей работе. При временном разрешении стриккамеры $\Delta t \sim 10^{-8} \mathrm{~s}$ фотосьемка велась с большого расстояния $\approx 125 \mathrm{~cm}$ на черно-белые фотопленки, что приводило к низкому пространственному разрешению получаемого на пленке изображения. По углу наклона изображения на фотограмме следует, что фотосъемка проводилась не в оптимальном режиме. По этим причинам каких-либо деталей в полученном изображении, кроме наличия первичной и вторичной ударной волны на фотограммах в работах $[18,19]$, обнаружить не удается. Другой причиной низкого качества изображения является использование подсветки в отраженных лучах EW от зеркала, установленного под прямым углом к оптической оси за EW для визуализации первичной ударной волны в начале электрического пробоя. Момент возникновения вторичной ударной волны $\left(t_{2} \sim 6 \mu \mathrm{s}\right)$ в работах $[18,19]$ приходится на заключительную фазу разряда. При этом ничего не сказано о наличии „темной“ фазы в начале процесса EW.

На рис. 13, $a, b$ приведена осциллограмма напряжения и тока $\mathrm{EW} \varnothing 100 \mu \mathrm{m}$ из $\mathrm{NiCr} L \approx 15 \mathrm{~mm}, C=2 \mu \mathrm{F}$, $U_{0}=10 \mathrm{kV}$, зарегистрированная на цифровом осциллографе Tektronix TDS 220. Для проводника из $\mathrm{NiCr}$ (также как и меди) $\varnothing 100 \mu \mathrm{m}$ провал на осциллограмме тока наступает раньше, чем для случая EW из меди $\varnothing 150 \mu \mathrm{m}$. Фотограмма пробоя на рис. $13, c$ регистрировалась на спектрозональной пленке типа $\mathrm{SN}-15$ за оранжевым фильтром OS-17. Скорость развертки составляла $3 \cdot 10^{3} \mathrm{~m} / \mathrm{s}$. Масштаб фотосъемки $1: 1.15$. Начиная с момента пробоя разрядного промежутка первичная ударная волна не видна. Изображение на фотограмме получается одноцветным с преобладанием одного лишь 

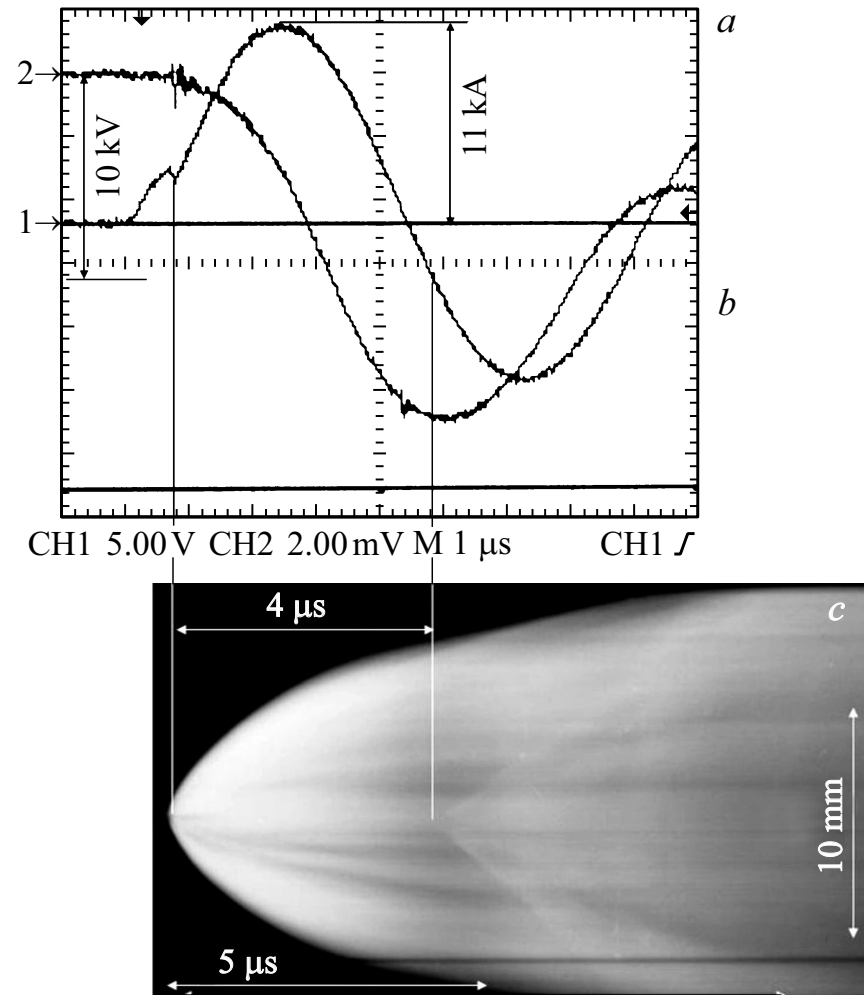

Рис. 13. Осциллограммы напряжения $(a)$, тока взрывающейся проволоки из $\mathrm{NiCr} \varnothing 100 \mu \mathrm{m}, L=15 \mathrm{~mm}(b)$; фотограмма пробоя на цветной спектрозональной пленке $\mathrm{SN}-15$, светофильтр OS-17 (c). Скорость развертки $3 \cdot 10^{3} \mathrm{~m} / \mathrm{s}$. Масштаб фотосъемки $1: 1.15$. Параметры разряда $U_{0}=10 \mathrm{kV}, C=2 \mu \mathrm{F}$.

синего цвета. Это связано с тем, что излучение из плазмы, образованной пробоем в парах $\mathrm{EW}$ из $\mathrm{NiCr}$, отличается от равновесного с преобладанием в коротковолновой (синей) части спектра. Это сказывается на качестве фоторегистрации на спектрозональную пленку, для которой мощное излучение в коротковолоновой части спектра является вредным даже при использовании фильтра OS-17 в процессе фоторегистрации. В полученном изображении также регистрируется „горячая точка“ на оси разряда в плоскости его симметрии, которая далее трансформируется в расходящуюся ударную волну с фронтом, близким к прямой линии. Однако область ее локализации во времени соответствует положению минимума тока в первом полупериоде. Механизм образования „горячей точки“ в плазме в этом случае отличается в своей динамике от случая EW из меди $\varnothing 150 \mu \mathrm{m}$ и будет рассмотрен далее.

Существует ряд гипотез и экспериментальных фактов [25-33], которые частично могут объяснить регистрируемое явление образования вторичной ударной волны в плазме, образованной $\mathrm{EW}$ из меди и $\mathrm{NiCr}$. Рассмотрим модель, предложенную в работе [31] при исследовании сильноточных разрядов, образованных EW из меди, вольфрама и алюминия в атмосфере. Емкость батареи конденсаторов составляла $C=144 \mu \mathrm{F}$, зарядное напряжение $U_{0}=12 \mathrm{kV}$. Взрывались проволо- ки длиной $L \approx 40 \mathrm{~cm}$ : медные $\varnothing 70 \mu \mathrm{m}$, вольфрамовые $\varnothing 200 \mu \mathrm{m}$, алюминиевые $\varnothing 140 \mu \mathrm{m}$. Период разрядного тока $T \approx 60 \mu \mathrm{s}$, максимальное значение силы тока в первом полупериоде $I_{\max } \sim 70 \mathrm{kA}$. Моментальные фотографии спектров с пространственным разрешением показали, что спектры разрядов, образованных EW из меди и вольфрама, имеют качественно общие черты. Для них характерен мощный континуум в центральной области и более слабый континуум во внешней зоне с наложенными на него линиями. При сопоставлении этих спектров оказалось, что линии, наложенные на континуум во внешней зоне, совпадают для этих разрядов. Эти линии принадлежат элементам окружающей среды воздуха. Линий, принадлежащих атомам металлов, в периферийных областях не обнаружено. Модель разряда [31] можно представить следующим образом: узкая центральная зона состоит из плазмы паров металла, внешняя зона - из плазмы компонент воздуха (двухзональная модель). Расширение световой зоны происходит за счет поступления в разряд новых порций воздуха. Исследование радиального распределения температуры для $\mathrm{EW}$ из меди и вольфрама показало [31], что наблюдается уменьшение температуры к оси разряда и к периферии, более горячей областью является промежуточная область. Оценка плотности плазмы показала [31], что воздух в разряд, образованный $\mathrm{EW}$ из меди и вольфрама, захватывается с плотностью $\rho \sim 0.1$ от атмосферной. Высокая температура плавления и испарения вольфрама и меди приводит к тому, что до момента пробоя с поверхности разогретого металла происходит термоэлектронная эмиссия. Электроны эмитируются в пространство, окружающее проволоку, и при наличии в окружающем пространстве достаточной концентрации свободных электронов происходит пробой по воздушной „шубе“ , окружающей проволоку. Пробой порождает ударную волну и следующую за ней токовую зону. Разрядный ток при этом протекает в основном по кольцевой зоне, окружающей проволоку, и в ней происходит омический нагрев и ионизация воздуха. Вследствие того, что перед токовой зоной идет ударная волна, после прохождения которой наступает разрежение, воздух в разряд захватывается с плотностью $\rho \sim 0.1$ от атмосферной. Центральная зона разряда состоит из плазмы паров металла и медленно расширяется со временем.

Можно предположить, что процесс кумуляции в плазме (образование „горячей точки“) обусловлен эффектом сжатия плазмы собственным магнитным полем - явлением $z$-pinch. [22-26]. В одной из первых работ Cousins и Ware [32] впервые продемонстрировали z-pinch при токах $10^{4}-2 \cdot 10^{4} \AA$. Подробнее об этом написано в обзоре W. Boctic [33]. Несмотря на большое количество опубликованных работ, связанных с явлением z-pinch, практически отсутствуют экспериментальные работы по исследованию данного явления в разряде, инициируемым взрывом короткой проволоки в атмосфере.

В работе [25] экспериментально исследовался $z$-pinch в аргоне при давлении $p_{0}=26.6-266 \mathrm{~Pa}$ 
(меньше атмосферного). Параметры разрядной цепи: $C=20 \mu \mathrm{F}, \quad U_{0}=15-35 \mathrm{kV}, \quad R_{0}=4.5 \mathrm{~cm}, \quad l_{0}=30 \mathrm{~cm}$, $F \approx(1-7) \cdot 10^{10} \mathrm{~A} / \mathrm{s}$. При данных параметрах характеристики шнура на стадии максимального сжатия определяются его начальными параметрами: напряжением $U_{0}$, длиной разрядного промежутка $l_{0}$, давлением газа в разряде $p_{0}$. Начальная скорость сжатия $V_{\text {in }}$ и длительность импульса излучения $\Delta t_{i}$ линейного z-pinch однозначно определяются величиной размерного комплекса $\Xi=U_{0}^{2} /\left(l_{0} p_{0}\right)[25]$, который может характеризовать режимы сжатия (однократного, двукратного и т.д) z-pinch в газе. Для $\Xi=0.85 \cdot 10^{6} \mathrm{~V}^{2} /(\mathrm{m} \cdot \mathrm{Pa})$ величина $V_{\text {in }}=1.65 \cdot 10^{3} \mathrm{~m} / \mathrm{s}[25]$.

Результаты, изложенные в работе [25] путем масштабирования, можно применить и для нашего случая. При запасенной энергии $E_{0} \sim 100 \mathrm{~J}$ и объеме $V_{0} \sim 4.6 \cdot 10^{-6} \mathrm{~m}^{3}$, как и в работе [25], удельный энерговклад в разряд имеет такое же значение $\sim 2 \cdot 10^{7} \mathrm{~J} / \mathrm{m}^{3}$. Если предположить, что воздух в разряд $\mathrm{EW}$ из $\mathrm{NiCr}$ в нашем случае захватывается с плотностью $\rho \sim 0.01$ от атмосферной (что справедливо для менее тугоплавкого, чем вольфрам, материала), то для $p_{0}=103 \mathrm{~Pa}$, $l_{0}=1.5 \cdot 10^{-2} \mathrm{~m}, U_{0}=10 \mathrm{kV}$ величина размерного комплекса $\Xi \approx 0.67 \cdot 10^{6} \mathrm{~V}^{2} /(\mathrm{m} \cdot \mathrm{Pa})$ характеризует режим однократного сжатия в разряде $\mathrm{EW}$ из $\mathrm{NiCr}$ в атмосфере.

В работах $[34,35]$ показано, что с учетом сил инерции сжатие столба плазмы собственным магнитным полем происходит с некоторой задержкой. Для случая пробоя в парах $\mathrm{EW}$ из $\mathrm{NiCr}$ сжатие плазмы может начаться в первом максимуме тока $\left(t_{0} \approx 2 \mu \mathrm{s}\right)$, когда энергия магнитного поля разряда $W_{m}$ составляет половину энергии, вводимой в разряд $W_{J}\left(W_{m} \sim 0.5 W_{J}\right)[25]$. При этом сжимающийся столб плазмы и сопутствующая ему ударная волна достигнут оси в момент $t_{1} \approx 4, \mu \mathrm{s}$, когда значение тока близко к нулю. В энергетическом балансе $z$-pinch энергия магнитного поля в динамике его сжатия играет существенную роль [25]. Определенную роль в процессе кумуляции может играть также геометрия разряда и разрядного промежутка. Как видно из интегральных фото разряда (рис. 8,9), в процессе пробоя плазма расширяется в радиальном направлении со сверхзвуковой скоростью. Но также как в модели инерциального сжатия в лазерном термоядерном синтезе (ЛТС) часть испаренного вещества с поверхности мишени (проволоки) в процессе пробоя движется наружу, но оставшаяся внутренняя часть движется к центру, сжимая плазму в область с $\Delta r \sim 0.5 \mathrm{~mm}$. При этом сжатие осуществляется не цилиндрической, а сферической ударной волной, которая в центре симметрии разрядного промежутка может сформировать „горячую точку“. Данное объяснение требует проведения дополнительных экспериментов.

Для случая пробоя в парах EW из меди $\varnothing 150 \mu \mathrm{m}$ сжатие расширяющегося столба плазмы начинается позже во второмом максимуме тока $\left(t_{0} \approx 4.5 \mu \mathrm{s}\right)$. При этом сжимающийся столб плазмы и сопутствующая ему ударная волна достигнут оси в момент времени $\left(t_{1} \approx 6 \mu \mathrm{s}\right)$ за вторым максимумом тока. Процесс кумуляции плазмы в этом случае происходит быстрее, чем в случае EW из $\mathrm{NiCr}$. Однако для того чтобы получить величину размерного комплекса $\Xi \approx 0.85 \cdot 10^{6} \mathrm{~V}^{2} /(\mathrm{m} \cdot \mathrm{Pa})$ и начальную скорость сжатия $V_{i n}=1.65 \cdot 10^{3} \mathrm{~m} / \mathrm{s}$, следует предположить, что воздух в разряд, образованный $\mathrm{EW}$ из меди, захватывается с плотностью $\rho \sim 0.005$ от атмосферной. В этом случае происходящие процессы приобретает характер „вакуумного взрыва“, так же как и в случае $\mathrm{EW}$ из алюминия [31].

B работе [18] F.D. Bennett's предложил другой механизм образования вторичной ударной волны. Основываясь на результатах численного моделирования в теории Wecken [36] он предположил, что вторичная ударная волна возникает как следствие отражения первичной ударной волны от границы плазмы. График формирования (r-t диаграмма) вторичной ударной волны теории Wecken приведен W. Müller в работе [37]. При этом яркий светящийся клин на фотограммах $\mathrm{EW}$-проволок из меди $\varnothing 157.5 \mu \mathrm{m}$ и серебра $\varnothing 127 \mu \mathrm{m}$ в работах $[18,19,38]$ соответствует радиальной сходящейся цилиндрической ударной волне, отраженной от центра. Кларк в работе [38], посвященной возбуждению ударных волн с помощью $\mathrm{EW}$ из серебра $\varnothing 127 \mu \mathrm{m}$, считает, что первичный пробой происходит на оси EW, и ударная волна распространяется по парам металла от оси. Когда ударная волна достигает скачка плотности на границе области, занимаемой парами металла, она отражается и движется по радиусу к центру. Затем ударная волна отражается от центра и расширяется по линейному закону. Однако, основываясь на результатах ранее цитируемой работы [31], данное объяснение не совсем правильное и требует дополнительного исследования с учетом геометрии разрядного промежутка и других факторов.

Другие наиболее интересные гипотезы „кулоновского взрыва“ [27,28], „теплового взрыва“ [30] крайне интересны, но они не соответствуют параметрам исследуемого разряда и не реализуются в условиях данного эксперимента.

\section{Заключение}

В настоящей работе предложена новая экспериментальная методика цветной фоторегистрации пространственно-временного развития канала искрового разряда в режиме самопробоя в атмосфере и пробоя инициированного взрывом проволоки при запасенной энергии $\sim 100 \mathrm{~J}$. Изложена методика сверхскоростной фоторегистрации с использованием как черно-белых, так и цветных аэрофотопленок. В результате исследований можно сделать вывод об улучшении качества изображения при использовании цветных и многослойных спектрозональных аэрофотопленок по сравнению с аналогичными черно-белыми пленками. Цифровая обработка негатива изображения, полученного на цветной спектрозональной пленке, позволяет визуализировать отдельные стадии и детали электрического разряда в 
атмосфере, которые не видны на аналогичных чернобелых пленках. Цветностной контраст и чувствительность в ближнем IR-диапазоне спектра таких пленок позволяют регистрировать в плазме импульсные процессы, когда плазма излучает в широком диапазоне спектра (вспышка континуума) $[23,24,26]$ в момент максимального сжатия (кумуляции) плазмы на оси разряда. При этом в разряде визуализируются мелкомасштабные неоднородности, ударные волны, сопровождающие процесс кумуляции, токопроводящий канал и его „оболочку“, зоны химических реакций, выбросы вещества в область разрядного промежутка. В исследуемом разряде удается реализовать режим кумуляции в виде сходящейся к оси разряда ударной волны, которая в момент максимального сжатия образует „горячую точку“ с $\Delta r \sim 0.5 \mathrm{~mm}$, которая далее трансформируется в расходящуюся ударную волну с фронтом, близким к прямолинейному на начальном этапе. Показано, что в данной геометрии может формироваться сходящаяся сферическая ударная волна, сжимающая плазму в малую область $\Delta r \sim 0.5 \mathrm{~mm}$. Параметры плазмы в момент максимального сжатия в данной геометрии до конца не изучены. Особый интерес представляет характер излучения (направленность) рентгеновских квантов с энергией $10-30 \mathrm{keV}$ в момент максимального сжатия. Предварительные результаты данных исследований уже получены и будут опубликованы в следующей работе.

Автор благодарен сотрудникам „Госниихимфотопроект“ Н.А. Грашиной и А.Г. Медведкову за помощь, оказанную в период выполнения работы [6]. В.P. Сороченко, М.Я. Щелеву за обсуждение экспериментальных результатов. В.В. Аполлонову, С.Ю. Казанцеву, Н.Б. Пономареву, А.С. Золотько за помощь в работе. Лично благодарю А.А. Рухадзе за поддержку настоящей работы.

\section{Список литературы}

[1] Саламандра Г.Д. Фотографические методы исследования быстропротекающих процессов. М.: Наука, 1974. 200 с.

[2] Дубовик А.С. Фотографическая регистрация быстропротекающих процессов. М.: Наука, 1964. 466 с. Изд. 2-е. М.: Наука, 1975. 456 с.

[3] Гарнов В.В., Шауро В.В. // Журн. науч. и прикл. фото- и кинематографии. 1963. Т. 8. № 4. С. 270-275.

[4] Иорданский А.Н. // Журн. науч. и прикл. фото- и кинематографии. 1957. Т. 2. № 1. С. 28-34.

[5] Aviation Week \& Space Technology 1990. Vol. 133. N 27. P. 43.

[6] Герасименко Н.И., Грашина Н.А., Медведков А.Г., Мещеряков А.Б., Плетнев Н.В. // ПТЭ. 1988. № 1. С. 212-215.

[7] Ванюков М.П., Исаенко В.И., Хазов Л.Д. // ЖТФ. 1955. Т. 25. Вып. 7. С. $1248-1256$.

[8] Kostinskiy A.Yu., Syssoev V.S., Bogatov N.A., Mareev E.A., Andreev M.G., Bulatov M.U., Makal'sky L.M., Sukharevsky D.I., Rakov V.A. // J. Geophys. Res. Atmos. Vol. 121. DOI: 10.1002/2016JD025079

[9] Насонов А.Г., Ланщман Л.С. // ПТЭ. 1984. № 2. С. 134-135.
[10] Стекло цветное оптическое. ГОСТ 9411-66. М: Государственный комитет стандартов Совета Министров СССР. $1972.55 \mathrm{c}$.

[11] Гончаренко Г.М. Труды МЭИ. Вып. 45. Электроэнергетика. М.: МЭИ, 1963. 169 с.

[12] Exploding wires. Vol. 1. N. Y.: Plenum Press, 1959. [Взрывающиеся проволочки. Т. 1. М.: ИЛ., 1963. 342 с.]

[13] Exploding wires. Vol. 2. N. Y.: Plenum Press, 1962. [Электрический взрыв проводников. Т. 2. М.: Мир, 1965. 341 с.]

[14] Протопопов Н.А., Кульгавчук В.М. // ЖТФ. 1961. Т. 31. C. 557-564.

[15] Vlasto's A.E. // J. Appl. Phys. 1967. T. 38. P. 4993-4998.

[16] Аполлонов В.В., Плетнев Н.В. // Квантовая электроника. 2012. T. 42. № 2. C. 130-139.

[17] Аполлонов В.В., Плетнев Н.В. // ЖТФ. 2013. Т. 83. Вып. 12. C. 67-80.

[18] Bennett F.D. // Phys. Fluids. 1958. Vol. 1. P. 347-352.

[19] Bennett F.D. // Phys. Fluids. 1958. Vol. 1. P. 515-522.

[20] Кадомцев Б.Б. Гидромагнитная устойчивость плазмы. Сб. Вопросы теории плазмы. Вып. 2 / Под ред. М.А. Леонтовича. М.: Гос. изд-во лит-ры по атомной науке и технике ГК по использованию атомной энергии СССР, 1963.

[21] Перегуд Б.П., Абрамова К.Б. // ДАН СССР. 1964. Т. 157. C. $837-840$.

[22] Курчатов И.В. // Атомная энергия. 1956. № 3. С. 65-75.

[23] Арцимович Л.А. Управляемые термоядерные реакции. М.: Физматлит, 1961. $467 \mathrm{c.}$

[24] Лукьянов С.Ю. Горячая плазма и управляемый ядерный синтез. М.: Наука, 1975. 408 с.

[25] Юсупалиев У. // Научн. конф. „Ломоносовские чтения“. Подсекция. Газодинамика, термодинамика и ударные волны. М.: МГУ, 2008. С. 231-243.

[26] Юсупалиев У., Шутеев Е.А., Юсупалиев П.У. // Прикладная физика. 2010. № 5. С. 40-53.

[27] Рухадзе А.А., Усупалиев У. // ЖТФ. 2004. Т. 74. Вып. 7. C. $127-128$.

[28] Орешкин В.И., Орешкин Е.В. // ЖТФ. 2017. Т. 87. Вып. 1. C. $34-38$

[29] Долгов А.Н., Клячин Н.А., Прохорович Д.Е. // ЖТФ. 2017. Т. 87. Вып. 4. С. 627-630.

[30] Саркисов Г.С., Этлишер Б., Ателан С., Руйе К., Шиканов А.С. // Письма в ЖЭТФ. 1995. Т. 61. Вып. 6. С. 471-476.

[31] Александров А.Ф., Савичев А.Т., Суров О.И., Тимофеев И.Б. // ЖТФ. 1980. Т. 50. Вып. 8. С. 1676-1681.

[32] Cousins S.W., Ware A.A. // Proc. Phys. Soc. 1951. Vol. 64B. P. 159.

[33] Winston H. Boctic // J. Fusion Energy. 1977. Vol. 1. N 1. P. $1-55$.

[34] Леонтович М.А., Осовец, С.М. // Атомная энергия. 1956. № 3. C. $81-83$.

[35] Любимов Г.А. // Вест. МГУ. Серия матем., механ., астроном., физ., хим. 1958. № 6. С. 13-17.

[36] Wecken F., Müche L. // „D'etonation d'une charge spherique“, Rapport 8/50, MU/DIZ, Saint Louis, France, 1950.

[37] Müller W. // Z. Physik. 1957. Bd. 149S. P. 397-411

[38] Кларк Г., Хикки Дюс., Кингсли Р., Вюркер Р. // Exploding wires. Vol. 2. N.Y.: Plenum Press, 1962. [Электрический взрыв проводников. Т. 2. М.: Мир, 1965. С. 202-208.] 